\title{
Aesthetic Reasoning: A Hermeneutic Approach
}

\author{
Nicholas Davey
}

\begin{abstract}
A BSTRACT This essay considers the foundations of reasonable evaluation in the arts. These we argue concern the relations that constitute (1) our experience of art, and (2) the ontology of the art work itself. The being of the artwork, the experience and the interpretation of it all involve over-lapping modes of part-whole relations. The experience of meaningfulness is not an experience of a singular object or framework of meaning as closed and complete but an experience of relational meaning whereby exposure to one set of meaningful relations transforms another in an on-going and open manner. This suggests that the experience of art itself provides the norms for reasonableness of evaluation. These norms are not rules in the sense of offering a method. They are characteristic of the features of an experience of meaningfulness itself. The essay suggests that the reasonableness of a response to a work can be considered in terms of (1) its appropriacy relative to the context of its own horizon and the horizon surrounding the production of the work; (2) its plausibility, that is, its internal coherence and consistency as a reading; (3) whether the structure of the response is consistent with, supplements, or expands the intelligible content of the work; and (4) whether it gives a sense of the latent possibilities still held within a work and intimates where the movement of a work's subject-matter might yet guide us.

KEYWORDS Phenomenological hermeneutics, Aesthetic reasoning, Gadamer
\end{abstract}

"Not all those who wander are lost."

J.R. R. TOLKIEN, The Fellowship of the Ring

\section{Thesis Statement}

Is it the case within the arts and humanities that anything can be said about anything? Is this the dark secret of hermeneutics as George Steiner claims? ${ }^{1}$ Are there norms for evaluation or are nihilism and relativism the inevitable consequence of "interpretive approaches" to art? This essay proposes that (1) an ontological conception of the relational being of an artwork as a singular multiplicity defends the cognate value of art and, furthermore, that (2) this ontological conception promises a response to the charge that in aesthetics no reasoning and evaluation is possible. Not only does the proposal promise the possibility of discursive evaluation and thereby justify claims concerning the cognitive value of art but it reveals how "interpretation" might add to the cognitive content of art. The being of an artwork and the activity of interpretation are mutually dependent. 


\section{Philosophical Orientation}

My argument is framed within the tradition of phenomenological hermeneutics. I am primarily concerned with a description of what is entailed in the act of understanding and evaluating an artwork. I am not going to discuss a philosophy of evaluation per se, as if that activity stands apart from the experience of a work. I shall take the experience of art as my cue.

As existing creatures, we live in and amongst a plethora of partwhole relations the totality of which can never be entirely surveyed. We struggle to articulate what we are already involved in. To interpret is to stand amongst, to be part of a series of complex relationships. In so far as we live in and amongst a variety of these ever shifting part-whole relations which we cannot transcend in any metaphysical sense, so we can only better understand our activities by changing our perspective from within the nexus of evaluations we are already involved. I want in this essay to suggest that the nature of aesthetic reasoning is best understood from what we do.

My emphasis upon the transitive is deliberate: reasoning does not imply a single method but a variety of interlocking ratios, rhythms, measures. The key to aesthetic reasoning is arguably not how we (as methodological subjects) apply critical or evaluative regulae to artworks but how the latter's own singular measures relate and lock into the measures that define the receiving horizons of a spectator.

\section{Questions of Framework}

What are the foundations of critical valuation in the visual arts? To raise the question of foundations is for some contemporary philosophical circles seemingly absurd. Post-modernist criticism which perhaps culminates in the aesthetics of Gianni Vattimo, dissolves any foundational concept of being and suggests that the whole notion of a validating ground for interpretation has collapsed. ${ }^{2}$ On the other hand, Joseph Margolis, an advocate of the opposing analytic tradition, has punctured the commonplace claim that a knowledge of artistic intentionality is the basis of artistic evaluation. ${ }^{3}$ Given the supremacy of historicist thinking and the collapse of faith in universal methods of evaluation, it might seem that "nihilism" and rampant subjectivism are the only outcomes. This has led thinkers such as Barbara Stafford to recover the credibility of aesthetics by translating subjective experiences into respectable academic phenomena, that is, by objectifying them as brain states. ${ }^{4}$ This manoeuvre too is ineffective. It simply dissolves the question of aesthetic meaning altogether. Does this leave us with a form of intellectual agnosticism: 
an unwillingness to commit altogether over the issue of evaluation and meaning in aesthetics? My claim may be modest but the issues are not. However, we should not despair. I cannot claim a killer counter-argument to nihilism but I do openly acknowledge that I am drawn to a cluster of intellectual intuitions which persuade me that critical reasoning within aesthetics is defensible. My argument is, then, that the ontological priority of discursive meaning over individual aesthetic response permits a consideration of the reasonable persuasiveness of aesthetic judgements. Let me outline a cluster of points which have a bearing on my position.

\section{Contextual Arguments}

(A) PHENOMENOLOGICAL PRIORITIES

It is noticeable that whenever the question of meaning and evaluation is raised, many critical commentators feel reticent about speaking until the question of methodological legitimacy is settled. Within the domain of aesthetics this is surely to put the cart before the horse. An art work suffers no crisis of procedural confidence before it presents its meanings. It simply addresses us. In this context, I would defend the claim that the experience of meaning is phenomenologically prior to the experience of purely "aesthetic" properties. Reflecting on what acknowledging this priority entails offers the basis for our case concerning the possibility of critical reasoning.

(B) THE RELATIONALITY OF MEANING

If the experience of meaning is phenomenologically prior, the relationality of meaning is foundational. Meaningfulness is both dependent upon the syntaxical relations of propositional discourse but also upon the perspectival nature of semantic relations two aspects of which are pertinent. First, speculative relationality: the meaningfulness of an image depends upon how it resonates with other networks of association. Its powers of suggestion depends upon placement in a wider speculative field. ${ }^{5}$ Meaningfulness depends just as much upon indeterminate extrinsic speculative relations as much as it does upon determinate intrinsic semantic relations. Second, meaningful contexts: the meaningfulness of a given field of words or images also depends upon the contextual perspective from which one approaches the initial set. To select a given work as meaningful assumes, phenomenologically speaking, engagement in such a field. It presumes a contextual selection, a prior sense of the ontology of the cultural world itself. ${ }^{6}$ Acquaintance with textual and historical information determines what is regarded as a plausible object 
of interpretation in the first place. Change the contextual orientation and you will change the meaningfulness of the interpreted object. To grant that a visual structure is meaningful requires a prior recognition that such structures are artefacts expressive of our own cultural formations. In short, meaningfulness requires contextual and speculative relationality. These relations define the character and boundaries of our cultural encounters. This suggests that relationality is at the core of the experience of meaning and is a key element of Gadamer's troublesome notion concept of a fusion of horizons (Horizontverschmelzung). This suggests that the experience of meaning is never on a singular plane but involves a fusion of semantically charged horizons.

To assert that relationality is at the heart of an experience of meaningfulness may appear to concede the argument to the nihilist. Does it not deny any stability of meaning? Does not hermeneutics itself give the game away when it asserts the ontological primacy of linguisticality in our encultured life-world. Gadamer makes the key claim: "not only is the world world only insofar as it comes into language, but language, too, has its real being only in the fact that the world is presented within it." Margolis makes a similar point: "the artifactual nature of the human is inconceivable without our being-in-the world that is "enlanguaged." ${ }^{8}$ The difficulty is obvious. If within the encultured world the word is logically primary, then, it follows that vagueness and ambiguity is also primary. If so, do we not crash into nihilism's wall? Is it the case that everything and therefore nothing can be said about a painting or a text? The riposte is "No". It is not obviously apparent but there is a door in nihilism's wall. The opening key relates to our initial assumption concerning the experience of meaningfulness. Let us now develop our principal argument.

\section{The Relational Character of Aesthetic Meaning}

It does not follow from the demolition of meaning-in-itself that the experience of meaningfulness is impossible. The point is that there can be no sense of the obscure or opaque in a verbal or visual image without some experience of meaningfulness. It is this experience of meaningfulness that Gadamer talks about when he states that "art addresses us". Relationality is, I propose, intrinsic to this claim: it offers a less obtuse notion of Horizontverschmelzung. What is at issue here is a realignment rather than a blending of horizons. The key to this nuance lies in the notion of meaningfulness itself. Its relational nature is illuminated by another Gadamerian term "application": the character of which lies in an ordinary language term: "I can relate to that ..." 
The "when" or moment of an art work addressing us may be utterly contingent, but the "that" of the event is far from arbitrary. It is specifically encultured and located. It pre-supposes a familiarity with the language of pictorial representation or abstraction. The enabling pre-suppositions that are characteristic of a becoming-encultured clearly do not entail becoming empathetic to the "mood" of a painter. Edward Hopper conveys a sense of stillness and isolation in his bar room inhabitants not by mysterious psychic transposition of inner feeling into paint but by deliberately abandoning individuating detail, i.e. he uses a public painterly conventions to convey the atmosphere of an environment. Familiarity with these conventions is a pre-condition of the work addressing one. Application therefore concerns the way in which the encultured and biographical horizons of the spectator are re-informed and re-aligned when they are opened to the affecting and effecting horizons of the work.

In the experience of art, the mode of relations that constitute an artwork's horizon come to permeate the horizon of relations that form a customary way of seeing in such a way as not to displace it but rather to achieve a new and significant permutation of it. One horizon or perspective inflects its other. This exchange or doubling inflects the one framework with the terms of its other. Hermeneutic doubling is a productive engagement the success of which is marked by the generation of a third element. This entails an obversion of form in which because of its engagement with a set of foreign relations, the home framework effectively becomes a qualitatively different world. Application has nothing to do with how something understood is subsequently applied to a body of different tasks ( i.e. understanding DNA coding and, then, realising its potential for forensic purposes). Rather, the experience of art speaking to us is the moment when experiential application becomes effective. Meaningfulness and application are matters that concern both bringinginto-relation and prompting realignments between relations.

The relational nature of meaningfulness is clearly at odds with any essentialist account of meaning. Relationality is behind the claim that an artwork is never complete. ${ }^{9}$ Art works embody part-whole structure and there is no logical stricture upon how the parts within a work's manifold can be aligned or re-aligned to form a different whole. Symphonic renditions provide a good example: consider the difference between Haitink, Barbarolli and Boulez in their renditions of Mahler's 7th Symphony. Furthermore, a change of position regarding my relation to that work can establish a new understanding of that work. This appeal to relationality establishes other points about how it is that art becomes culturally effective. 
The open nature of constituting relationships in a work permits it to achieve a greater historical effectiveness or adaptability. This is in effect to say that an essentialist account of meaning threatens historical redundancy i.e. it can only operate in horizons that are attuned to the reception of fixed meaning. Both points re-enforce the claim that meaningfulness and application are relational. The next step in my argument is to claim that the relational is reasonable and therefore provides an encultured basis for critical evaluation in the arts. What justifies this step?

Reasonableness relates philologically not to a fixed structure but rather to ratios, to elements brought into relation, ordered or regulated in various ways. This reasonableness (or order of ratios) is not an interpretation imposed on art from the outside but reflects the structure of the art work as a part-whole composition. This fits with Gadamer's notion of hermeneutics as "thinking with" the movements within a work, descending into the play of its elements. Any internal evaluation of a work will have to be consistent with the symmetry of relations that form what elsewhere I have referred to as a work's measure..$^{10}$ Understanding a work or a thinker entails participating in an appropriate pattern of thought. This does not concern grasping a fixed "essence" but knowing how to question further, partaking in the field of cognitive movement that the question invokes. It is question of entering into the field of play constitutes that work. Although the occasion of subjective experience may be arbitrary, the response is not. The fact that an art work addresses a spectator demonstrates that the spectator already participates unknowingly in a horizon of concerns that he or she subsequently becomes knowingly re-acquainted with. This suggests that art works and their evaluation can claim a trans-subjective legitimacy because they are ontologically grounded in collectively received historical conventions and social practices.

The claim concerning the very reasonableness (i.e. relationality) of aesthetic interpretation emerges intact from critiques of the notion that the meaning of any aesthetic idea cannot be resolved into a fixed concept. Such irresolvability suggested to Kant that decisions concerning the possible combinations of meaning relating to an aesthetic idea could only be arrived at on the basis of subjective preference. Many thinkers have struggled with the consequences of this claim. It implies that there can be no determinate knowledge in aesthetics. John Milbank argues that this is a false dichotomy indicative of a mesmerizing but fictional distinction between pure and empirical reason. However, Milbank implies that Kant's aesthetic ideas should be accorded the status of what Gambatista 
Vico identified as poetic or concrete universals. If the proliferating alignments of meaning associated with an aesthetic idea cannot be reduced to a determinate concept, is an instability of meaning for aesthetic ideas (and by implication, subject-matters) unavoidable? On one level, such instability is advantageous to hermeneutics as it allows for a proliferation of meaning. However, the burden of the question remains. Is any clustering of meaning arbitrary and subjective? This strikes at a fundamental issue for philosophical hermeneutics.

Does not the open irresolvable nature of interpretation suggest that there is no knowledge in art? In Gadamer's words, "this (question) can hardly be recognised if, with Kant, one measures the truth of knowledge by the scientific concept of knowledge and the scientific concept of reality". ${ }^{11}$ John Millbank's observation that Kant's aesthetic ideas have the formal characteristics of Vico's poetic or cultural universals suggests that subject-matters, aesthetic ideas and poetic universals share certain ontological characteristics: each transcends its material sensuous instantiation, each emerges in history, and each is subject to historical and cultural mediation. Furthermore, Millbank's insight provides Gadamer with the cognitive weight he needs to attribute to subject-matters in order to demonstrate (1) the subject-matter of art does indeed have a knowledge value and that (2) the opposite of Kant's rigid notion of conceptual knowledge is neither subjectivism nor relativism. As we have argued, poetic or concrete universals may not be logically a priori but they are culturally $a$ priori: they "invoke the specific ways in which human beings commonly appropriate their experience". ${ }^{12}$ Aesthetic ideas and subject matters are thus historically transmitted concrete universals that ground both tradition and its sensus communis. Reasoning within the boundaries of such universals, "while less definable than abstract reason ... (is) ... no less exacting according to its own mode". ${ }^{13}$ The argument substantiates our claim that interpretation can draw out and extend the cognitive content of a work's subject matter and strengthens our argument concerning the reasonableness of debate surrounding the experience of art.

\section{Conclusion}

What are the foundations of reasonable evaluation in the arts? This paper has argued that they must concern the relations that constitute (1) our experience of art, and (2) the ontology of the art work itself. The being of the artwork, the experience, and the interpretation of it all involve modes of over-lapping part-whole relations. The experience of meaningfulness is, we have argued, not an experience of a singular object or of a frame- 
work of meaning as closed and complete but an experience of relational meaning whereby exposure to one set of meaningful relations transforms another in an on-going and open manner. I have tried to argue that the experience of art itself provides the norms for reasonableness of evaluation. These norms are not rules in the sense of offering a method. They are characteristic of the features of an experience of meaningfulness itself. The reasonableness of a response to a work can be considered on four levels. An interpretation can be assessed on the following terms:

(1) its appropriacy relative to the context of its own horizon and the horizon surrounding the production of the work,

(2) its plausibility: that is, its internal coherence and consistency as a reading

(3) whether the structure of its response is consistent with, supplements or expands the intelligible content of the work.

(4) Whether it gives a sense of the latent possibilities still held within a work and intimates where the movement of a work's Sachen might yet guide us.

J.R. R. Tolkein's remark that "Not all those who wander are lost" aptly describes the predicament of those who seek to converse with and evaluate art. Contrary to the pessimistic claims of some post-modern criticism, we have no need to feel lost or that we are unavoidably falling towards " $\mathrm{x}$ ". 14 If the art-work does indeed address us it does so because we are already (1) situated in horizons of meaning which define our historical epistemé and (2) entwined in evolving collective and personal auto-biographical narratives which an art work is capable of transforming. What the experience of art de facto demonstrates is that we have not arrived but continue to find our way.

Aesthetic reasoning from the perspective of hermeneutics is not a question of method, it is a question of participating in the relations that constitute a work and of finding and responding to their measure. Here the axiom of thinking with a work comes into its own. It does not mean re-constructing a work in the manner of Dilthey's hermeneutics. Nor does it mean re-thinking it in the sense of Collingwood's historical reconstruction of its rationality. Thinking with a work concerns discerning its measure or rhythms and following through its own logic perhaps well beyond its initial articulation. However, the point of this endeavour is to extend the logic of the work to that point when it starts to open unexpected possibilities for insight in the horizons which one takes to the work. Aesthetic reasoning and critical evaluation are important not in and for 
themselves: They are important to aesthetic education as a means for bringing a work's logic into critical engagement with that of our own horizons, that is, for making things happen within that horizon. When an experience of art brings about a new alignment of horizons, it is not so much a recovery as a discovery of the unstated but perfectly reasonable objective possibilities for thought which are inherent within zones of intellectual sensibility which constitute the complex relationality of our trans-linguistic, trans-cultural historical horizons. After all, is it not the gift of poiesis that it can render the abstractions of these horizons in discernibly particular terms? This lends credence to our argument that art does indeed speak to us because of the relationality that constitutes the character of our being. What asserts itself in the experience of art as evident "has not been proved and is not absolutely certain." ${ }^{15}$ "It asserts itself by reason of its own merit within the possible and the probable."16 It is, we claim, precisely, the relationality of meaningfulness that make the experience of the possible and the probable possible. If we fail to articulate clearly what such relationality consists of, its forms and patterns, then it is not just the future of aesthetics that will be compromised, but that of the humanities as well.

\section{Notes}

1. George Steiner, Real Presences (London: Faber and Faber, 1989), 53.

2. Gianni Vattimo: "No one ever tells the truth, the whole truth, and nothing but the truth. Every statement entails a choise of that which we take to be relevant, and this choice is never disinterested." Farewell to Truth (New York: Columbia University Press, 2011), 9.

3. Joseph Margolis, The Arts and the Definition of the Human (Stanford: Stanford University Press, 2009), 95.

4. Barbara Maria Stafford, Echo Objects: The Cognitive Work of Images (Chicago: University of Chicago Press, 2007). Similar moves were made in earlier attempts to reduce the aesthetic experiences to instances of social behaviour. Both forms of reduction fail to surmount the gap that will remain between firstperson states and third-person states.

5. Hans-Georg Gadamer, Truth and Method (London: Sheed and Ward, 1989), 466-70.

6. Margolis op cit p. 95 .

7. Hans-Georg Gadamer, Truth and Method (London: Sheed and Ward, 1989), 443 .

8. Margolis op. cit p. 19. 
9. Hans-Georg Gadamer: "There is no absolute progress and no final exhaustion of what lies in a work of art. The experience of art knows this of itself." Truth and Method (London: Sheed and Ward, 1989), 100.

10. See Nicholas Davey, "Getting the Measure: Language and Reasoning in Philosophical Hermeneutics”, Internationales Jahrbuch fur Hermeneutik, 10 (Tübingen: Mohr Siebeck, 2011), 123-42.

11. Hans-Georg Gadamer, Truth and Method (London: Sheed and Ward, 1989), 97-98.

12. John Millbank, The Word Made Strange (Oxford: Blackwell, 1998), 128-36. 13. Ibid.

14. Friedrich Nietzsche, The Will to Power (London: Weidenfeld and Nicolson, 1968), Section 1:1.

15. Hans-Georg Gadamer, Truth and Method (London: Sheed and Ward, 1989), 485 .

16. Ibid. 